\title{
Assessment of TGF- $\beta$ and IL10 levels in human brucellosis
}

\author{
Mousa Mohammadnia-Afrouzi ${ }^{1}$, Soheil Ebrahimpour ${ }^{2 *}$ \\ ${ }^{1}$ Department of Immunology, School of Medicine, Babol University of Medical Sciences, Babol, Iran \\ ${ }^{2}$ Infectious Diseases and Tropical Medicine Research Center, Health Research Institute, Babol University of Medical Sciences, Babol, Iran
}

\section{ARTICLE INFO \\ Received 05 November 2017 Accepted 18 December 2017}

\section{Keywords:}

brucellosis,

ELISA,

TGF- $\beta$,

IL-10.

\begin{abstract}
The recent study assessed TGF- $\beta$ and IL-10 as immunosuppressive cytokines of the cell mediated immunity (CMI) against Brucella in the serum of some brucellosis patients. Serum from 15 patients and 15 healthy individuals were obtained, and then cytokine concentrations above were investigated. Concentrations of TGF- $\beta$ induced in the serum of acute patients $(89.73 \pm 15.55 \mathrm{ng} / \mathrm{ml})$ were higher than healthy group $(58.86 \pm 17.89 \mathrm{ng} / \mathrm{ml}$, $\mathrm{P}<0.0001)$. While, no significant differences were found in the concentration of IL-10 between two groups. Based upon the findings of our study, the contribution of these cytokines to the pathobiology of infection had been shown. Therefore, assessment of immunosuppressive cytokines as TGF- $\beta$ and IL-10 levels may be a potential diagnostic strategy for patients with brucellosis.
\end{abstract}

\section{INTRODUCTION}

Brucellosis is a febrile illness induced by intracellular bacteria of the genus Brucella. The bacteria brings about infection by replicating and surviving within the antigen presenting cells (APCs) such as the macrophages. Brucella induces virulence factors that modify phagolysosome fusion with Brucella containing vacuoles (BCV), as well as apoptosis and cytokine secretion (TNF $\alpha$, IFN- $\gamma$ ) [1,2]. In such diseases, clinical manifestations are related to immune responses, especially in cell mediated immunity (CMI). The CMI-type cells include CD4+, CD8+ T-lymphocytes and CD4+ CD25+ FoxP3+Treg cells (Tregs). Various studies in infectious diseases showed that Treg cells play a crucial role in the maintenance of immunological homeostasis and pathogenesis [3]. In the other words, these cells have the capability to regulate immune responses. Regulatory $\mathrm{T}$ cells use different mechanisms to exert their activity as they contain cell contact-dependent mechanisms, plus they produce of immunoregulatory cytokines such as transforming growth factor- $\beta$ (TGF- $\beta$ ) and IL-10 $[4,5]$. The TGF- $\beta$ superfamilies are engaged in the suppression of some cellular and molecular processes, including differentiation, proliferation, angiogenesis and adhesion [6]. TGF- $\beta$ cytokines are important suppressors of helper T cells and a potent inhibitor of macrophage activation, but stimulate the function of Treg cells. IL-10 is secreted by Treg cells, this in turn inhibits cytokine

\footnotetext{
* Corresponding author

e-mail: drsoheil1503@yahoo.com
}

production in TNF- $\alpha$ and IFN- $\gamma$ versus excessive Th1, Th 2 and $\mathrm{CD} 8+\mathrm{T}$ cell responses in the pathogenesis of infections $[7,8]$. Many studies show that TGF- $\beta$ and IL-10 have been enhanced in Helicobacter pylori infection or gastric mucosal inflammation [9]. Other researches suggest that TGF- $\beta$ modifies the progress of malaria infections in mouse, as well as some other parasitic infections $[10,11]$. Despite what has been noticed in infectious disease research, the presence and role of TGF- $\beta$ and IL-10 in Treg cells regulation, is still an issue of argument. Therefore, in this study, concentrations of these immunosuppressive cytokines were evaluated in brucellosis as a devastating infection.

\section{MATERIALS AND METHODS}

\section{Study population}

Our study was conducted in the teaching hospital of Rouhani (affiliated with Babol University of Medical Sciences) from August 2016 to June 2017. The study was approved by the Ethics Committee of Babol University (no. 1982), and the participants provided written informed consent. Fifteen patients ( 10 men and 5 women) aged 44.66 \pm 15.39 years (range 10-70 years) with brucellosis were included. Fifteen healthy age- and gender-matched volunteers with no history of infectious diseases, aged $42 \pm$ 12.74 years (range 15-73 years), were enrolled (10 men and 5 women) as controls. The inclusion criteria was acute brucellosis. Exclusion criteria included endocarditis and 
osteomyelitis and pregnancy. Infection was diagnosed via positive blood culture, standard agglutination test (SAT) titer $\geq 1: 320$ and 2-mercaptoethanol (2-ME) titer $\geq 1: 80$ with typical clinical findings of brucellosis.

\section{Collection of blood, preparation of serum and cytokine quantitation}

A total of $3 \mathrm{ml}$ fasting venous blood was obtained from patients and healthy controls. Blood samples were allowed to clot for $30 \mathrm{~min}$ before centrifugation and then the samples were centrifuged at $1000 \times$ gravitational units $(\mathrm{g})$ for $10 \mathrm{~min}$ to isolate serum. The sera was frozen and stored at $-20^{\circ} \mathrm{C}$ until use for assessing TGF- $\beta$ and IL-10 levels. The concentration of these immunosuppressive cytokines were measured by enzyme-linked immunosorbent assay (ELISA) kits from (eBioscience, San Diego, CA, USA). Furthermore, assays of cytokines were performed in duplicate according to the manufacturer's specifications.

\section{Statistical analysis}

Statistical analysis was performed using the Mann-Whitney U test with GraphPad Prism, version 5.00, software for Windows (GraphPad software, La Jolla, CA, USA). Data are presented as means \pm S.D. Investigation of the differences between the means was to be significant when $\mathrm{P}<0.05$.

\section{RESULTS}

\section{Demographic characteristics of study subjects}

The demographic characteristics of the subjects, are shown in Table 1 . Nine $(60 \%)$ patients were residents of rural areas. Eight $(53.3 \%)$ cases had SAT titer $\geq 1: 320$ and seven $(46.6 \%)$ SAT titer $\geq 1: 160$. Moreover, five $(33.3 \%)$ patients had $2 \mathrm{ME}$ titer $\geq 1: 160$, and ten $(66.6 \%) 2 \mathrm{ME}$ titer $\geq 1: 80$. All 15 cases had active infection and were not taking medicine. The active patients had higher levels of WBC $(11.6 \pm 3.27)$ compared with healthy controls $(7.18 \pm 2.02$, $\mathrm{P}<0.0001)$.

\section{Mean TGF- $\beta$ and IL-10 serum levels}

In the current study, we determined the concentration of TGF- $\beta$ and IL-10 in serum of infected cases using ELISA kits, so as to answer the question whether immunoregulatory cytokines are produced and elevated in brucellosis positive patients. As demonstrated in Fig. 1, concentrations of TGF- $\beta$ in serum of active patients $(89.73 \pm 15.55 \mathrm{ng} / \mathrm{ml})$ were higher than in the healthy group $(58.86 \pm 17.89 \mathrm{ng} / \mathrm{ml}$, $\mathrm{P}<0.0001$ ). Moreover, as demonstrated in Fig. 2, the concentration of IL-10 was not significantly different in the aflicted $(87.4 \pm 27.77 \mathrm{pg} / \mathrm{ml})$ compared to healthy controls $(87.06 \pm 25.61 \mathrm{pg} / \mathrm{ml}, \mathrm{P}=0.8)$.

Table 1. Demographical features of subjects

\begin{tabular}{|l|c|c|}
\hline \multicolumn{1}{|c|}{ Characteristic } & $\begin{array}{c}\text { brucellosis - positive } \\
\text { patients }\end{array}$ & controls \\
\hline Number & 15 & 15 \\
\hline Sex (Male/Female) & $10 / 5$ & $10 / 5$ \\
\hline Age, year, Mean \pm SD & $44.66 \pm 15.39$ & $42 \pm 12.74$ \\
\hline Residency (Rural/ Urban) & $9 / 6$ & $8 / 7$ \\
\hline
\end{tabular}

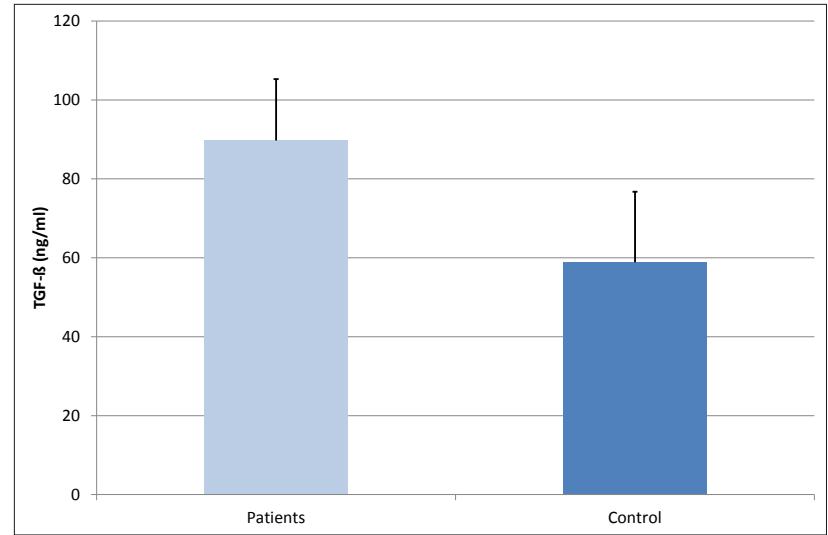

Figure 1. Concentrations of TGF- $\beta$ in the serum of active patients and of the healthy group

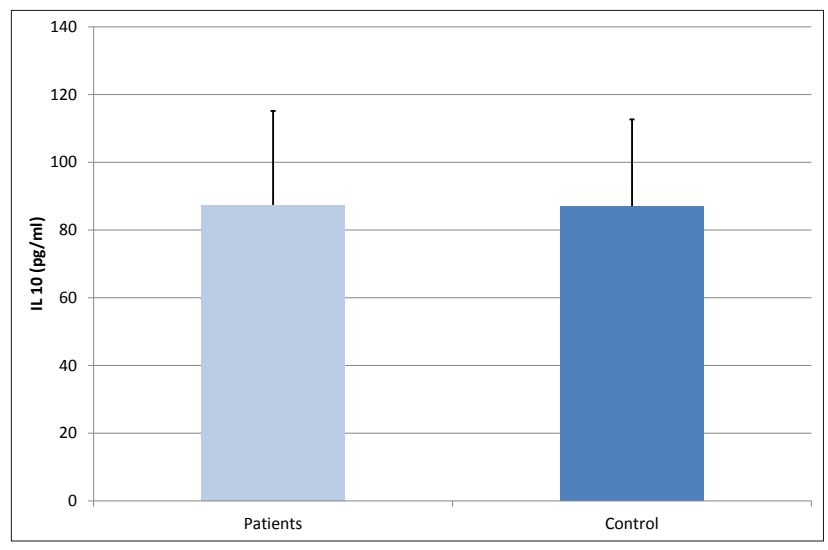

Figure 2. Concentration of IL-10 and healthy controls

\section{DISCUSSION}

Despite evidence of the involvement of CMI in brucellosis, many important questions remain on this issue. Among these are which molecules and cells are involved in immunity. As we know, Brucella, an intracellular gramnegative bacterium, has different evasion strategies to avoid the innate and adaptive immune responses [12]. Among the various immune cells, regulatory $\mathrm{T}$ cells also suppress immune responses to pathogens as Brucella. These cells represent about $10 \%$ of human CD4+ T cells. Previous studies had been shown that regulatory $\mathrm{T}$ cells increased significantly in acute and chronic forms of human brucellosis, compared with healthy individuals [13]. Moreover, disorders of the helper $\mathrm{T}$ cells responses and anergy have been found in the chronic form of brucellosis [14]. Regulatory $\mathrm{T}$ cells mediate their regulatory functions by producing immunosuppressive cytokines such as TGF- $\beta$ and IL-10. In the recent study, the concentration of these inhibitory cytokines was determined in the serum of patients. We indicated that Treg cells of brucellosis-positive patients produce higher levels of TGF- $\beta$, but lower levels of IL- 10 .

Similar to our results, some studies showed that in chronic brucellosis, the impressive increased production of TGF- $\beta 1$ in serum might generate the suppression of immune responses such as that of T cells, with prolongation of infection course in these patients [15]. Moreover, previous work has revealed that in the acute form of hantavirus infection, 
significantly elevated percentages of TGF- $\beta 1$ are seen. We also saw that IL-10 levels did not increase during active infection (compared to healthy controls), but significantly decreased in the late phase of the disease [16]. In agreement with our findings, another study confirmed the higher levels of TGF- $\beta$ in peripheral blood mononuclear cells (PBMCs) of cases with active tuberculosis (TB) than in healthy control individuals. Herein, TGF- $\beta$ decreased the ability of monocytes to contain the growth of Mycobacterium tuberculosis. As this cytokine also promotes inflammation and fibrosis, TGF- $\beta$ has a critical role in the pathology of $M$. tuberculosis infection [17].

Other researches had demonstrated in active brucellosis patients, increased IL-12p40 percentages and unchanged IL-10 levels. Therefore, the significantly increased IL-12p40 levels with the normal IL-10 levels confirm the important fact that acute brucellosis -positive patients develop helper T cell responses, especially in Th1 [18]. Still, Chaiyaroj et al. described TGF- $\beta$ levels that significantly declined in the plasma of patients with severe malaria [19]. It is known that plasma levels of TGF- $\beta$ and IL-12 in malaria cases regulate the balance between pro-inflammatory cytokines (IL-1, IFN- $\gamma$ ) and anti-inflammatory cytokines (IL-10). In some malaria studies, an inverse correlation was seen in both percentages of TGF- $\beta$ alongside IL-12 with the severity of malaria. Thus, TGF- $\beta$ is an immunosuppressive cytokine with known involvement in the protection against the development of severe malaria infection [19].

The limitations of the present study were the investigation of only acute form of infection together with two cytokines. In this way, consideration of the presence other cytokines in different forms of the disease is suggested.

\section{CONCLUSION}

Our results show enhanced amounts of TGF- $\beta$ and unchanged concentration of IL-10 in brucellosis -positive patients, suggesting the involvement of these cytokines in the immune process of infection. Therefore, assessment of immunosuppressive cytokines such as TGF- $\beta$ levels may be a potential diagnostic strategy for patients with brucellosis.

\section{ACKNOWLEDGEMENTS}

The authors would like to acknowledge the staffs in Department of Infectious Diseases.

\section{CONFLICT OF INTEREST}

The authors declare that they have no conflict of interests.

\section{REFERENCES}

1. Skendros P. et al.: Cell-mediated immunity in human brucellosis. Microbes Infect. 2011;13:134.

2. Gomez G. et al.: Host-Brucella interactions and the Brucella genome as tools for subunit antigen discovery and immunization against brucellosis. Front Cell Infect Microbiol., 3,1,2013.

3. Mangodt TC. et al.: The role of Th17 and Treg responses in the pathogenesis of RSV infection. Pediatr Res.,78,483,2015.

4. Mohammadnia-Afrouzi M. et al.: Altered microRNA Expression and Immunosuppressive Cytokine Production by Regulatory T Cells of Ulcerative Colitis Patients. Immunol Invest. 2016;45:63.

5. López-Abente J. et al.: Functional Mechanisms of Treg in the Context of HIV Infection and the Janus Face of Immune Suppression. Front Immunol. 2016;7:192.

6. Seeger P. et al.: The TGF- $\beta$ superfamily in dendritic cell biology. Cytokine Growth Factor Rev. 2015;26:647.

7. Couper KN. et al.: IL-10: the master regulator of immunity to infection. J Immunol. 2008;180:5771.

8. Sabat R. et al.: Biology of interleukin-10. Cytokine Growth Factor Rev. 2010;21:331.

9. Beswick EJ. et al.: Role of Gastric Epithelial Cell-Derived Transforming Growth Factor $\beta$ in Reduced CD4(+) T Cell Proliferation and Development of Regulatory T Cells during Helicobacter pylori Infection. Infect Immun. 2011;79:2737.

10. Omer FM. et al.: Activation of Transforming Growth Factor $\beta$ by Malaria Parasite-derived Metalloproteinases and a Thrombospondin-like Molecule. J Exp Med. 2003;198:1817.

11. Gough NR: Enhancing and Inhibiting TGF- $\beta$ Signaling in Infection. Science Signaling.8,ec9,2015.

12. de Figueiredo P. et al.: Pathogenesis and Immunobiology of Brucellosis: Review of Brucella-Host Interactions. Am J Pathol. 2015;185:1505.

13. Bahador A. et al.: Frequencies of CD4+ T Regulatory Cells and their CD25 high and FoxP3 high Subsets Augment in Peripheral Blood of Patients with Acute and Chronic Brucellosis. Osong Public Health Res Perspect. 2014;5:161.

14. Skendros P. et al.: Diminished percentage of CD4+ T-lymphocytes expressing interleukine-2 receptor alpha in chronic brucellosis. J Infect. 2007;54:192.

15. Elfaki MG., Al-Hokail AA: Transforming growth factor $\beta$ production correlates with depressed lymphocytes function in humans with chronic brucellosis. Microbes Infect. 2009;11:1089.

16. Sadeghi M. et al.: Cytokine expression during early and late phase of acute Puumala hantavirus infection. BMC Immunol. 2011;12:1.

17. Guyot-Revol V. et al.: Regulatory T cells are expanded in blood and disease sites in patients with tuberculosis. Am J Respir Crit Care Med. 2006;173:803.

18. Rodríguez-Zapata M. et al.: Human brucellosis is characterized by an intense Thl profile associated with a defective monocyte function. Infect Immun. 2010;78:3272.

19. Chaiyaroj SC. et al.: Reduced levels of transforming growth factor- $\beta 1$, interleukin-12 and increased migration inhibitory factor are associated with severe malaria. Acta Trop. 2004;89:319. 